\title{
Ion Storage Techniques and Time-of-Flight Mass Spectrometry in Physical Forensic Science
}

\author{
D.M. Chambers, K.I. Grace
}

This article was submitted to 2000 IEEE/EIA International

Frequency Control Symposium \& Exhibition, Kansas City, MO, June $6-9,2000$

Lawrence

Livermore

National

Laboratory

June 27, 2000

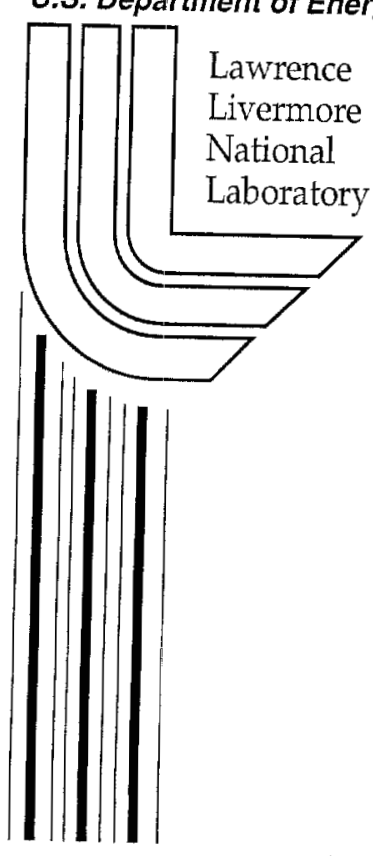




\section{DISCLAIMER}

This document was prepared as an account of work sponsored by an agency of the United States Government. Neither the United States Government nor the University of California nor any of their employees, makes any warranty, express or implied, or assumes any legal liability or responsibility for the accuracy, completeness, or usefulness of any information, apparatus, product, or process disclosed, or represents that its use would not infringe privately owned rights. Reference herein to any specific commercial product, process, or service by trade name, trademark, manufacturer, or otherwise, does not necessarily constitute or imply its endorsement, recommendation, or favoring by the United States Government or the University of California. The views and opinions of authors expressed herein do not necessarily state or reflect those of the United States Government or the University of California, and shall not be used for advertising or product endorsement purposes.

This is a preprint of a paper intended for publication in a journal or proceedings. Since changes may be made before publication, this preprint is made available with the understanding that it will not be cited or reproduced without the permission of the author.

This work was performed under the auspices of the United States Department of Energy by the University of California, Lawrence Livermore National Laboratory under contract No. W-7405-Eng-48.

This report has been reproduced directly from the best available copy.

Available electronically at http://www.doc.gov/bridge

Available for a processing fee to U.S. Department of Energy

And its contractors in paper from

U.S. Department of Energy

Office of Scientific and Technical Information

P.O. Box 62

Oak Ridge, TN 37831-0062

Telephone: (865) 576-8401

Facsimile: (865) 576-5728

E-mail: reports@adonis.osti.gov

Available for the sale to the public from

U.S. Department of Commerce

National Technical Information Service

5285 Port Royal Road

Springfield, VA 22161

Telephone: (800) 553-6847

Facsimile: (703) 605-6900

E-mail: orders@ntis.fedworld.gov

Online ordering: http://www.ntis.gov/ordering.htm

\section{OR}

Lawrence Livermore National Laboratory

Technical Information Department's Digital Library

http://www.llnl.gov/tid/Library.html 


\title{
ION STORAGE TECHNIQUES AND TIME-OF-FLIGHT MASS SPECTROMETRY IN PHYSICAL FORENSIC SCIENCE
}

\author{
David M. Chambers and Louis I. Grace* \\ Forensic Science Center, Lawrence Livermore National Laboratory, Livermore CA
}

*Current address: Department of Chemistry, The Hebrew University of Jerusalem, Jerusalem, Israel

\section{Introduction}

Effective investigative analysis requires proper selection of sample-collection procedures, preservation, and analysis methods. To achieve these objectives it is essential to tailor the collection and analysis methods to the application requirements, which are constrained by different parameters such as analysis time, sample concentration, matrix interferences, and analyte stability (e.g., surface activity ("stickiness") and chemical reactivity). In addition, method optimization must be accomplished without compromising sample integrity. Maintaining sample integrity requires minimizing and characterizing contamination as well as reducing sample degradation and loss to prevent both false positive and negative detection, respectively. When specific constraints are defined, depending on target chemical(s) and application scenarios, it is sometimes necessary to modify or develop new equipment and methods to best satisfy the application requirements.

For this work, we are interested in real-time monitoring of airborne chemicals, which are commonly referred to as volatile organic compounds (VOC). Although there are a number of techniques for remote analysis of VOCs, many of these applications do not provide the specificity and sensitivity needed in real-time application scenarios. For example, spectroscopic techniques are capable of providing low part-per-billion volume/volume ( $\mathrm{ppb} \mathrm{v} / \mathrm{v})$ detection if a compound is distributed over a large area, however, they provide limited compound structural information. A different approach using air monitoring mass spectrometry can provide more specific chemical information in terms of compound molecular weight and structural information, however, preconcentration is required to achieve low ppb detection.

As a result of these limitations, most air monitoring applications rely on remote collection using either gasbottle or sorbent collection. These collection approaches can be effective because they permit preconcentration. However, VOCs with vapor pressures lower than 100 Torr at $20^{\circ} \mathrm{C}$ possess a significant surface activity that makes collection and release difficult to control at low concentrations. Therefore, careful preparation of collectors and special validation procedures are often necessary to account for analyte adsorption or degradation loss at chemical/surface interfaces such as on container or valve walls.

One collection approach that we believe serves as a benchmark for remote analysis is solid phase microextraction (SPME). SPME uses a $100-\mu \mathrm{m}$ fiber that is coated with a sorbent for collection. Because of the fibers small size it can be directly inserted into a gas chromatograph injection port, permitting efficient transfer of even semivolatile compounds for gas chromatography/mass spectrometry (GC/MS) analysis. In the example shown in Fig. 1, we demonstrate detection of VOCs down to the part-per-trillion (ppt) v/v range. Shown is a comparison of air analysis for a chemistry laboratory and a class 100 (i.e., $\leq 100$ particles $/ \mathrm{ft}^{3}$ of $<0.5 \mathrm{~mm}$ o.d.) clean room. Similarities between the two VOC signatures are attributed to environmental pollution. Differences denote specific chemical activity.

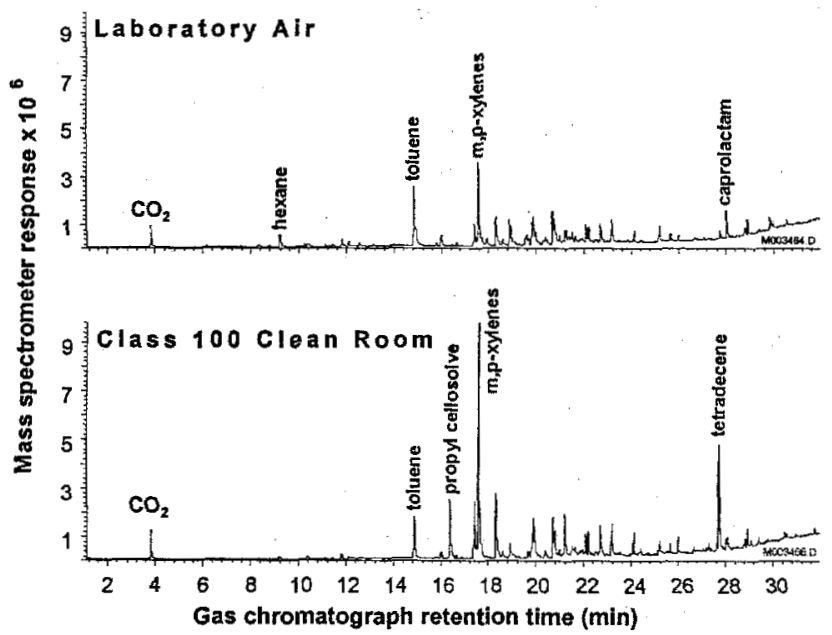

Figure 1. State-of-the-art sorbent collection by SPME permits monitoring down to $\mathrm{ppt} \mathrm{v} / \mathrm{v}$ levels and redefinition of cleanliness. This approach serves as a sensitivity benchmark for new monitoring approaches under development.

Although SPME circumvents many of the problems associated with VOC collection, it does not provide for real-time analysis. However, in a number of applications we require an analysis capability for transient low concentration targets in a humid air matrix. One such application is in the search for non-volatile explosives, 
which can not be collected and directly analyzed. As shown in the mass chromatogram in Fig. 2 of the outgas analysis for 1,3,5-triamino-2,4,6-trinitrobenzene (TATB), a non-volatile explosive used in some weapon high-explosive formulations, toluene is the primary chemical outgassed. Toluene is not a byproduct or decomposition product, but rather, a synthesis aid that is trapped during the final synthesis step of TATB. Other applications include monitoring fast reactions (explosions, incineration, process chemical treatment) and drive-by or fly-by analysis (clandestine manufacturing, damage assessment).

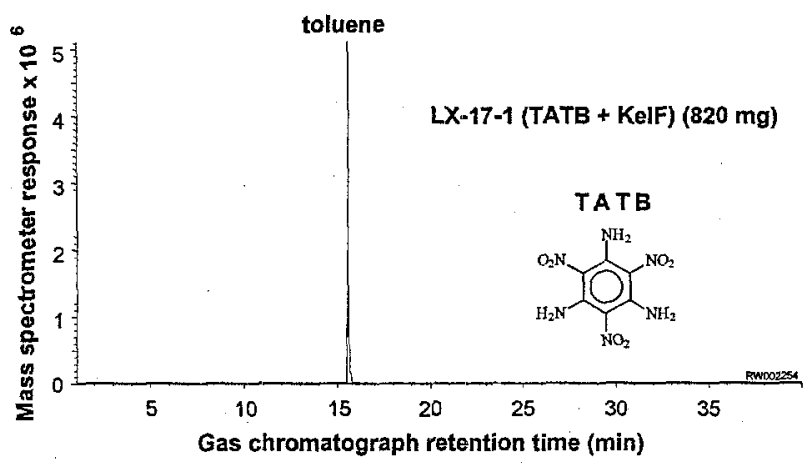

Figure 2. Outgas analysis for TATB in LX-17-1, a nonvolatile plastic bonded explosive, reveals significant toluene response. Toluene is a unique synthesis aid that remains held in the TATB crystalline structure and slowly outgasses with age.

To address these issues, our group has been developing an ion storage trap/time-of-flight mass spectrometer (IS/TOF-MS) similar to those described by others, ${ }^{1,2,3}$ but for performing real-time monitoring of volatile and semivolatile compounds in air. We selected this approach because the IS/TOF-MS combination is capable of providing both fast analysis and sample preconcentration needed for trace-air analysis. Specifically, the IS, which serves as the pulsed extraction source for the TOF-MS, can also be used to preconcentrate target chemicals to lower detection limits. TOF/MS provides for real-time monitoring whereby an entire mass spectrum typically can be produced in less than $100 \mu \mathrm{s}$. Given the relatively long storage-time capability of the IS (i.e., $10 \mathrm{~ms}$ to greater than $1 \mathrm{~s})$, the IS/TOF-MS system achieves a duty cycle that approaches $100 \%$. The transmission efficiency in the IS/TOF-MS is equally as high because the entire ion population accumulated in the IS device can be extracted toward the TOF/MS.

${ }^{1}$ Chien, B.M.; Michael, S.M.; Lubman, D.M. Anal. Chem. 1993, 65, 1916-1924.

${ }^{2}$ Michael, S.M.; Chien, B.M.; Lubman, D.M. Anal Chem, 1993, 65, 2614-2620.

${ }^{3}$ Chambers, D.M.; Grace L.I.; Andresen, B.D. Anal. Chem. $1997,69,3780$.
To achieve successful coupling of these two ion focusing devices we opted to modify ion trap operation. This approach involves the extraction of stored ions with spatial and velocity characteristics that can be focused by the TOF-MS for optimum resolution and sensitivity. In this work we discuss the theory and operation of the IS as a pulsed extraction source for TOF-MS analysis of VOCs. Upon optimization, we evaluate instrument performance in terms of sensitivity, resolution.

\section{Experimental}

\section{Design and operation of the IS/TOF-MS}

Fig. 3 shows a schematic of the IS/TOF-MS. Two instrument prototypes were developed based on this theory of operation-a laboratory prototype and a smaller transportable version. Many of the fundamental studies and modifications used to understand and optimize the IS/TOFMS operation were performed on the laboratory system. This information was then used to produce the transportable instrument that shown in Fig. 4.

For analysis air is drawn into the instrument through a single stage inlet in the side of the source envelope, passes through a Teflon guide tube, and then enters the IS through a small hole, $1.0 \mathrm{~mm}$ in diameter, in the ring electrode. Electrons from a heated filament are accelerated through the center of the trap, where they ionize the incoming air sample. Initially, the endcaps of the IS are held at ground potential and a radio frequency (RF) potential is applied to the ring electrode to trap ions. After the desired accumulation or storage time has passed, the RF potential is clamped to zero, and high-voltage pulses are applied simultaneously to the exit and entrance endcaps, accelerating the ions out of the IS. The ions then pass through an Einzel lens, between two steering plates, and into the time-of-flight analyzer. They are then reflected in the electrostatic mirror (i.e., reflectron) to strike the detector at the opposite end of the flight tube. The flight tube is equipped with a liner to keep the drift region at the same potential as the ion accelerating potential.

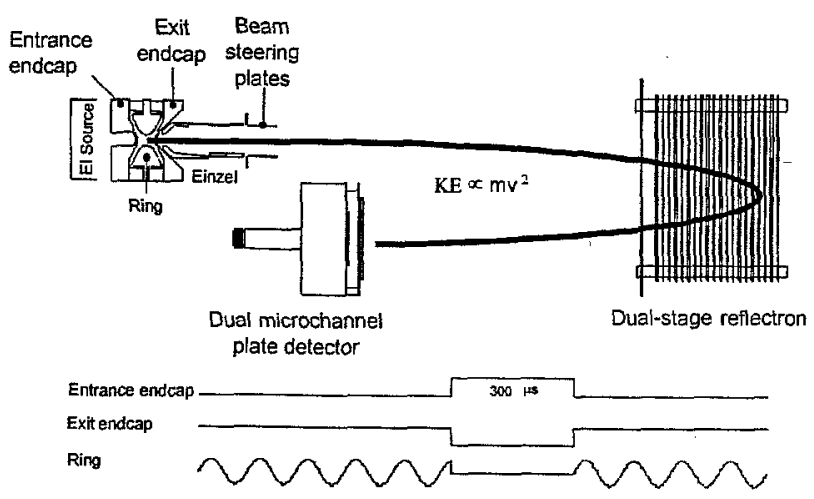


Figure 3. Schematic of operation for IS/TOF-MS instrument.

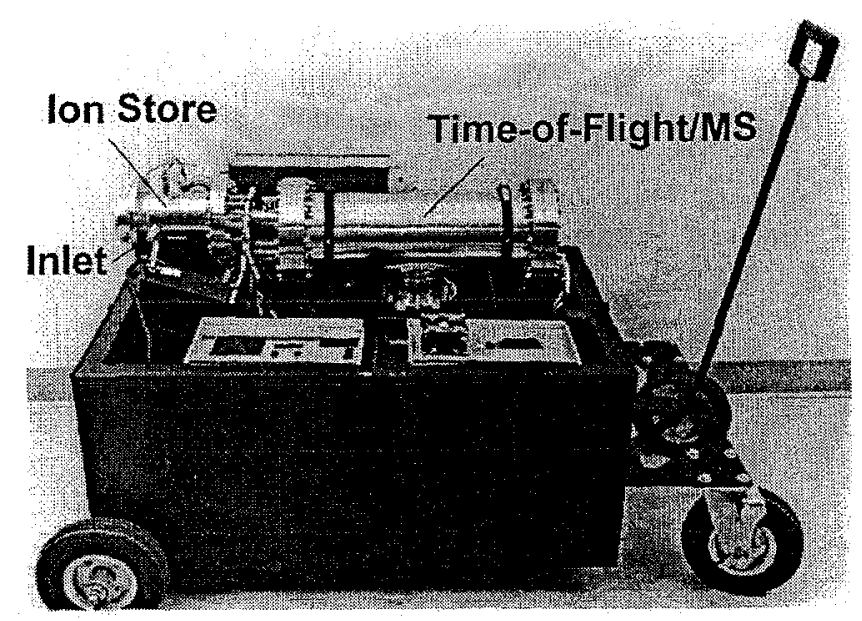

Figure 4. Photograph of transportable IS/TOF-MS.

To minimize noise from stray ions and electrons, the electron gun is tied to the exit endcap and is, thus, deactivated during the extraction pulse. In addition, to prevent saturation of the detector by stray ions that drift into the flight tube during the ion accumulation period, one of the steering plates is kept at a potential such that ions passing through are deflected away from the detector. When the ions are extracted from the IS, a pulse is applied to the deflection plate to steer the ions toward the detector. The extraction and gate pulses are made wide enough to allow the heaviest ions to reach the detector so that the ion trajectories are not disturbed by changing electric fields. Once this time has elapsed, the endcaps are grounded, the steering plate voltage is reset, and the RF potential is turned on.

\section{Discussion}

For this system we are using a Paul trap, which is a quadrupolar ion trap, as the ion storage unit. This trapping device consists of three electrodes with rotational symmetry about the $z$-axis. The center ring electrode is a doughnutshaped electrode with an inside surface forming a hyperboloid of one sheet. The endcaps are oriented on either side of the ring electrode forming a hyperboloid of two sheets.

Operation of the trap used in the IS/TOF-MS is different from that of a standard mass analyzer, which typically employs mass-selective axial ejection to generate a mass spectra. In these standard systems, this process is achieved by applying a low-frequency AC voltage to the endcap electrodes while the RF potential on the ring electrode is ramped. As the ions approach their stability limit with increasing $\mathrm{RF}$, the $\mathrm{AC}$ voltage promotes ejection along the z-axis by exciting ion secular motion (a micromotion independent of the "orbit). The primary drawback of this process is that only half the ion cloud is ejected toward the detector. The other half is ejected in the opposite direction toward the ionization source. Furthermore, ion ejection of this type is susceptible to space-charge interference, which can interfere with ion secular motion, resulting in decreased resolution and shifts in apparent mass.

In the IS/TOF-MS the ion trap acts solely as a storage device, therefore eliminating the need for mass-selective axial ejection. Instead, the entire ion packet is extracted toward the exit endcap with an applied extraction voltage. This approach eliminates the importance of ion secular motion, permitting the trap to be filled without regard to ion space-charge interference of resolution and mass accuracy. This is demonstrated in Fig. 5 on the laboratory system where the IS is used to collect three different types of ions; 1) xenon, a permanent gas, 2) benzene, a VOC, and 3) chloroethylethylsulfide (CEES), a semi-volatile organic compound (semi-VOC). For each specie the response levels off with ion storage time. This leveling off represents the ion trap storage capacity, which is determined by the ion trap parameters that define ion "orbit", ion space charge and neutral interactions, and ionization processes. The drop in Xe response at longer storage times results from charge exchange with lower ionization potential compounds. The inset graph is the mass spectrum expanded about the benzene ion $(\mathrm{m} / \mathrm{z} 91)$, which demonstrates no distortion of resolution (i.e., peak width) or mass accuracy (i.e., flight time).

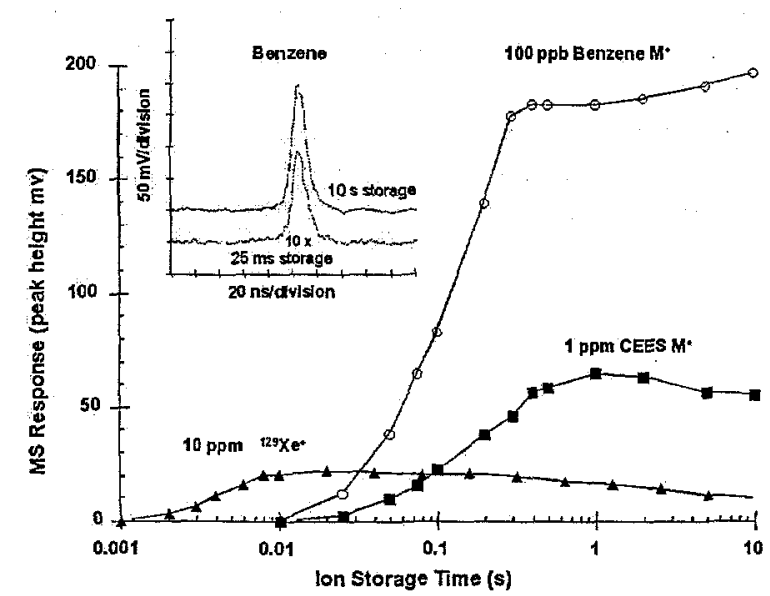

Figure 5. Effect of storage time on signal for $10 \mathrm{ppm}$ xenon $(\mathrm{m} / \mathrm{z} 129), 100 \mathrm{ppb}$ benzene $(\mathrm{m} / \mathrm{z} 78)$, and $1 \mathrm{ppm}$ CEES $(\mathrm{m} / z$ 125). These responses were compared on the laboratory prototype with an inlet flow of $2.5 \mathrm{~mL} / \mathrm{min}$ and IS pressure of $0.105 \mathrm{mT}$ Torr.

\section{Ion store operation}

Ion extraction is the most important process needing optimization because it is key in establishing transmission efficiency and resolution in the TOF-MS. Relatively speaking, ion traps can create broad time-dependent spatial and kinetic energy distributions, especially for low molecular weight species. The approach used to minimize 
these spreads is to extract ions of a particular phase-space characteristic best suited for this TOF-MS configuration. Consequently, most of this work has involved optimizing the IS conditions and extraction procedures. The resulting configuration incorporates three modifications made to the IS that include 1) phase synchronization of the extraction pulse with respect to the ring electrode RF, 2) clamping of the ring electrode RF drive potential, and 3) bipolar extraction of the jon packet. The effect of each of these parameters on signal and resolution is discussed below.

\section{Phase Synchronization}

Although the ions in the trap follow a complicated orbit that is defined by a number of ion trap parameters, their spatial and velocity distribution is directly tied to the RF cycle. ${ }^{4}$ Ions with higher $\mathrm{q}_{\mathrm{z}}$ values have orbits that take them farthest from the center of the trap as depicted in Fig. 6. The velocities of these high $\mathrm{q}_{z}$ ions are influenced most by RF phase, where as ions with low $\mathrm{q}_{z}$ that approach 0.1 remain unaffected. In general, as the RF approaches the maximum positive potential, $\Psi=90^{\circ}$, ions are directed the greatest radially but toward the center of the trap. Conversely, as the $\mathrm{RF}$ approaches the maximum negative potential, $\Psi=270^{\circ}$, they become directed the greatest axially.
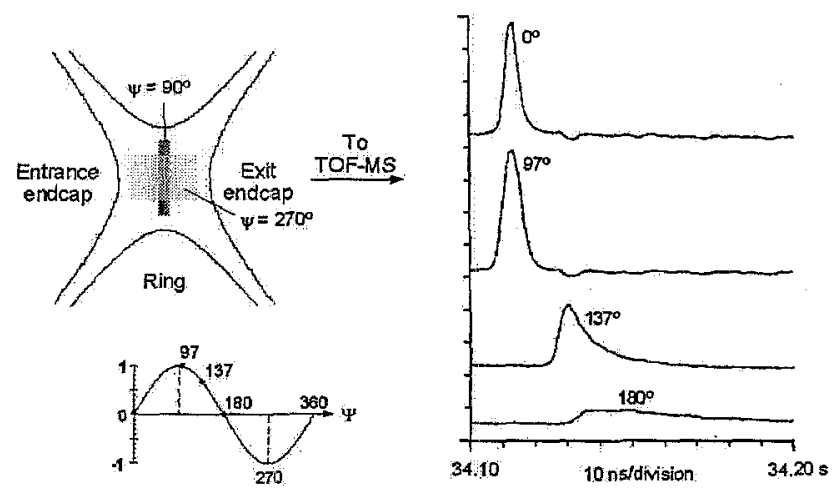

Figure 6. For high $\mathrm{q}_{\mathrm{z}}$ ions the ion cloud spatial distribution is most influenced by RF phase as indicated in the crosssectional view of the ion trap cavity. As a result, the RF phase at which extraction occurs can greatly influence resolution and sensitivity for high $\mathrm{q}_{\mathrm{z}}$ ions as shown for the perfluorotributylamine fragment at $\mathrm{m} / \mathrm{z} 69\left(\mathrm{q}_{\mathrm{z}}=0.46\right)$.

This change in ion velocity with $R F$ phase can affect TOF-MS resolution, especially for high $\mathrm{q}_{z}$ ions. An example of this relationship is shown in the Fig. 6 mass spectra of the $\mathrm{m} / \mathrm{z} \quad 69$ fragment ion from perfluorotributylamine $\left(\mathrm{q}_{z}=0.46\right)$. Phase synchronization of the extraction pulse with the RF drive potential is performed by triggering the extraction pulse from the same

\footnotetext{
${ }^{4}$ Todd, J.F.J.; Waldren, R.M;; Freer, D.A.; Turner, R.B. Int. J. Mass Spectrom. Ion Processes 1980, 35, 107-150.
}

clock used in the RF generator. At RF phases between 0 and $90^{\circ}$ the ion peak is the narrowest, like that shown for the trace taken at $0^{\circ}$. Within this range we expect ion trajectories to be directed toward the center of the trap and heading axially toward the ring electrode with decreasing velocity. ${ }^{5}$ As the RF phase reaches $180^{\circ}$ the ion peak shifts to a longer time and exhibits a high-time tail. At $180^{\circ}$, velocities are at a maximum and the ion cloud is expanding axially. $^{51}$ Ions extracted at this phase are closest to the endcaps and can be extracted with a low extraction potential $^{48,50}$, however, because the spread of the ion packet is relatively large, complete sampling and focusing of the ion packet is difficult in the TOF-MS, resulting in decreased transmission efficiency and resolution.

\section{$R F$ Clamping}

As shown in Fig. 6 the RF field significantly influences resolving power for high $\mathrm{q}_{z}$ ions. However, as ions are extracted out of the trap, RF focusing fields, which are strongest at the ion trap boundary, ${ }^{6}$ can still influence ion movement. A change in potential during the extraction process will have the greatest effect on low $\mathrm{m} / \mathrm{z}$ ions. As a result, it is common practice to turn off the voltage input to the RF oscillator during the extraction. This approach for gating the RF field, even with a low $Q$ circuit, requires several cycles to completely extinguish the RF envelope. A new design was developed in which the RF oscillator is shored to ground, thus immediately extinguishing the RF potential. Oscilloscope traces comparing the behavior of the two circuits are shown in Fig. 7. With the new clamping arrangement the RF can be cut off in approximately $10 \mathrm{~ns}$.

Shown in Fig. 8 are expanded mass spectra for the PFTBA fragment at $m / z 69\left(q_{z}=0.46\right)$ extracted at an $R F$ phase of $\Psi=45^{\circ}$ with and without clamping of the RF potential on the ring electrode. Clamping the RF increases the flight time by $25 \mathrm{~ns}$ and narrows the peak width (i.e., FWHM) by 4 ns. With no RF clamping the velocity distribution is broadened and flight time is shortened because the extraction takes place as the RF is driving to a greater positive potential.

\footnotetext{
${ }^{5}$ Todd, J.F.J.; Waldren, R.M.; Bonner, R.F. Int. J. Mass Spectrom. Ion Processes 1980, 34, 17-36.

${ }^{6}$ Jones, J.A.; Yost, R.A. Proceedings of the $42^{\text {nd }}$ ASMS Conference on Mass Spectrometry and Allied Topics; Chicago, IL 1994, p. 222.

${ }^{7}$ Fulford, J.E.; March, R.E. Int. J. Mass Spectrom. Ion Phys. 1979, 30, 373-378.
} 
Conventional RF Damping Circuit.

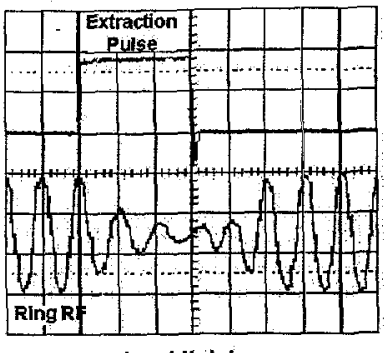

$1 \mu$ s/division

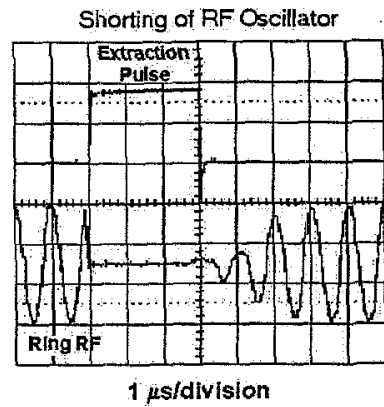

Figure 7. Comparison of RF waveforms and corresponding extraction pulses resulting from two different $\mathrm{RF}$ circuits. The trace from the conventional RF damping circuit is typical of a parallel driven resonance circuit where the drive is shut off requiring several cycles to decay. The trace taken of the new clamping circuit is achieved by shorting the stored energy in the oscillator to ground with a transistor switch.

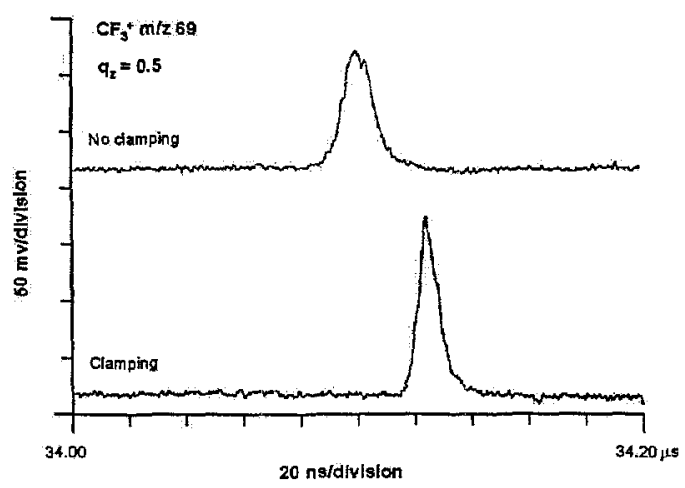

Figure 8. Effect of RF clampling on peak shape for perfluorotributylamine ion fragment at $\mathrm{m} / \mathrm{z} 69(\mathrm{qz}=0.045$ ). Extraction was performed at an RF phase of $45^{\circ}$ on the laboratory prototype instrument.

\section{Bipolar Extraction}

We found the endcap extraction voltage to be another operation that can dispurse the ion packet during analysis. Typically, ions are either extracted from the IS by applying a voltage pulse to either the entrance or exit endcap. ${ }^{8}$ Thus, when an extraction voltage is applied to just one electrode, a parabolic field gradient is formed that focuses radially distributed ions to a crossover point outside the exit endcap. However, it is possible to create a linear accelerating field in the trap by pulsing both endcaps simultaneously with equal but opposite voltages. This is illustrated in the ion trajectory simulations shown in Fig. 9, which were obtained using the Simion program. ${ }^{9}$ Bipolar extraction, as we call it, at relatively high field strengths of $1333 \mathrm{~V} / \mathrm{cm}$ was found to yield the best sensitivity and resolution. This behavior is characteristic of focusing an ion packet with a relatively small spatial distribution, yet significant kinetic energy spread. In operation of the IS/TOF-MS, the use of bipolar instead of unipolar extraction increased resolution by a factor of 3 for low $\mathrm{m} / \mathrm{z}$ ions. As discussed above, higher $\mathrm{m} / \mathrm{z}$ ions are distributed more to the center of the trap.

\section{Unipolar Extraction}

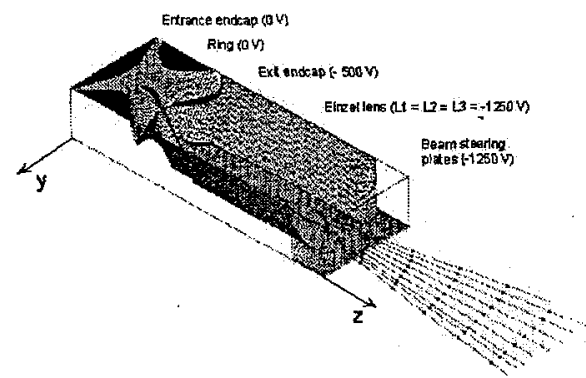

\section{Blpolar Extraction}

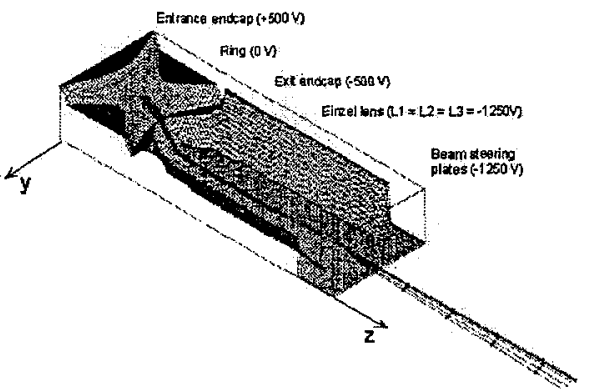

Figure 9. Ion trajectory models comparing unipolar and bipolar extraction. The initial ion starting plane runs diagonally through the trap center extending $\sim 3.5 \mathrm{~mm}$. Ions . are give not initial kinetic energy. Trajectories are drawn with $1-\mu$ s time markers.

\section{Instrument performance Sensitivity}

As discussed in the introduction, detection limits demonstrated with sorbent collection serve as our

\footnotetext{
${ }^{8}$ Waldron, R.M.; Todd, J.F.J. Int. J. Mass Spectrom. Ion Processes 1979, 29, 315-335.

${ }^{9}$ Dahl, D.A.; Delmore, J.E.; Appelhans, A.D. Rev. Sci. Instrum. 1990, 61 607-609.
} 
performance benchmark. However, as we approach detection at the low- and sub-ppb level, environmental pollution becomes significant. At these low levels it is necessary to background subtract contributions from environmental pollution.

Shown in Table I is a comparison of detection limits achieved for the transportable and laboratory prototype instruments. Detection limits were determined by extrapolating the instrument response to that concentration that gives a signal to noise ratio of 3 . We expect higher sensitivity in the transportable instrument resulting from lower divergence loss with a shorter flight tube. In fact, the transportable instrument did provided low detection limits for the most volatile compounds, however the sensitivity for semi-VOCs was considerably lower. We believe this difference is related to a lower volume flow rate of the vacuum system in the transportable instrument. At this time we are uncertain on how to improve detection of semiVOCs within the design constrains of the transportable platform. Attempts to passivate the inlet and moderate increase in inlet flow rate did not substantially improve detection of the semi-VOCs.

Table I. Comparison of limits achieved between the laboratory prototype and the transportable instruments

\begin{tabular}{|l|c|c|c|}
\hline \multicolumn{1}{|c|}{ Compound } & Ion observed & \multicolumn{2}{|c|}{$\begin{array}{c}\text { Detection Limit } \\
\text { prototype } \\
\text { transportable }\end{array}$} \\
\hline freon 11 & $(\mathrm{M}-\mathrm{Cl})^{+}$ & 2 & 0.7 \\
\hline $\begin{array}{l}\text { perfluoromethyl- } \\
\text { cyclohexane }\end{array}$ & $\left(\mathrm{CF}_{3}\right)^{+}$ & 4 & 0.4 \\
\hline benzene & $(\mathrm{M})^{+}$ & 2 & 8.0 \\
\hline toluene & $(\mathrm{M}-\mathrm{H})^{+}$ & 0.9 & 3.3 \\
\hline $\begin{array}{l}\text { chloroethylethyl- } \\
\text { sulfide }\end{array}$ & $(\mathrm{M})^{+}$ & 194 & $>4 \mathrm{ppm}$ \\
\hline
\end{tabular}

\section{Resolution}

Because heavier ions are confined more closely to the center of the IS than lighter ones, and because the we employ a reflectron, the width of the ion packet changes a little with mass, and, thus, resolution is somewhat mass dependent. Fig. 10 shows mass spectra for a xenon standard exhibiting a resolution of nominally $1600 \mathrm{~m} / \Delta \mathrm{m}$ at FWHM. This data was collected using a 200-ms accumulation time and averaging 7 scans. This resolution far exceeds that needed for standard VOC analysis, where mass analysis does not generally exceed $400 \mathrm{amu}$. Also included in Fig. 10 are the measured relative abundances and the actual natural abundances for the $\mathrm{Xe}$ isotopes. The measured abundances are within few percent of the actual, and most of the error results from background chemical interference.

\section{Conclusions}

Operation of the trap as a pulsed extraction eliminates many of the limitations that accompany operating the trap

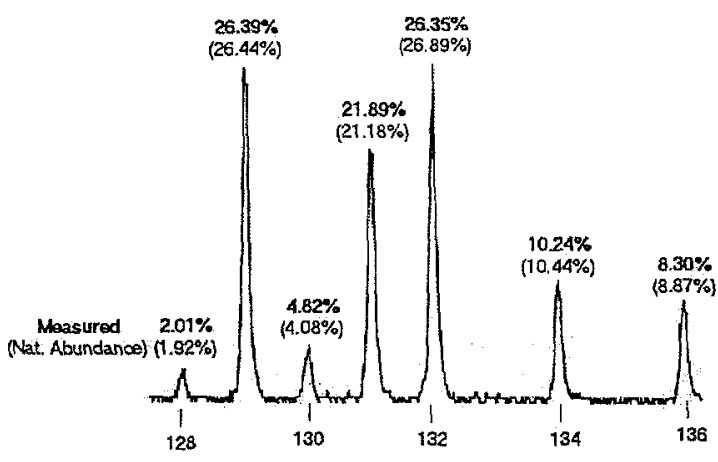

Figure 10. Xenon standard in air analyzed with the transportable instrument using a 200 -ms storage time and averaging 7 traces. Resolution is nominally $1600 \mathrm{~m} / \Delta \mathrm{m}$ at FWHM.

using mass selective axial ejection. As pulsed extraction source, the IS can be operated under high ion/ion and ion/neutral collision conditions without regard to perturbing ion secular motion. This permits overfilling of the IS and the use of air as a collisional damping gas with little effect on resolution and mass accuracy. A subsequent advantage of using air as a collisional damping gas is that it enhances ionization efficiency by providing a mechanism for chemical ionization.

In addition to ion storage, the ion trap can be operated to deliver an ion packet with a spatial and kinetic energy distribution well suited for time-of-flight analysis. This mode of operation enhances sensitivity and resolution permitting the TOF-MS analyzer to be used effectively for real-time air monitoring. Among the different changes to trap operation needed for optimal operation, those modifications that minimize dispersion of the ion packet during extraction have the greatest effect on performance. Together these modifications, which include 1) phase synchronization, 2) RF clamping and 3) bipolar extraction, permit resolution of up to $1600 \mathrm{~m} / \Delta \mathrm{m}$ at FWHM and detection into the low ppb range for VOCs. Sensitivity for semi-VOCs is significantly lower and is attributed to adsorption loss in the IS envelop. We are currently investigating solutions to this limitation.

\section{Acknowledgement}

The authors would like to acknowledge the following for their support of this work; Hugh Gregg for general analytical support, Bob Peterson for firmware development, Stan Thomas and Gregg Soto for development of drive electronics and Mike Wiefel for instrument fabrication support.

This work was performed under the auspices of the U.S. Department of Energy by University of California Lawrence Livermore National Laboratory under contract No. W-7405-Eng-48. 